Gustafsson, Henrik, Hill, Andrew P.

ORCID: https://orcid.org/0000-0001-6370-8901, Stenling, Andreas and Wagnsson, S. (2016) Profiles of perfectionism, parental climate, and burnout among competitive junior athletes.

Scandinavian Journal of Medicine \& Science in Sports, 26 (10). pp. 1256-1264.

Downloaded from: http://ray.yorksj.ac.uk/id/eprint/1394/

The version presented here may differ from the published version or version of record. If you intend to cite from the work you are advised to consult the publisher's version: http://onlinelibrary.wiley.com/doi/10.1111/sms.12553/abstract

Research at York St John (RaY) is an institutional repository. It supports the principles of open access by making the research outputs of the University available in digital form. Copyright of the items stored in RaY reside with the authors and/or other copyright owners. Users may access full text items free of charge, and may download a copy for private study or non-commercial research. For further reuse terms, see licence terms governing individual outputs. Institutional Repository Policy Statement

\title{
RaY
}

Research at the University of York St John

For more information please contact RaY at ray@yorksj.ac.uk 


\section{Profiles of perfectionism, parental climate, and burnout among competitive junior athletes}

\begin{tabular}{|r|l|}
\hline Journal: & Scandinavian Journal of Medicine and Science in Sports \\
\hline Manuscript ID: & SJMSS-O-389-15.R1 \\
\hline Manuscript Type: & Original Article \\
\hline Date Submitted by the Author: & 03-Aug-2015 \\
\hline Complete List of Authors: & $\begin{array}{l}\text { Gustafsson, Henrik; Karlstad University, } \\
\text { Hill, Andrew; York St John University, } \\
\text { Stenling, Andreas; Umeå University, } \\
\text { Wagnsson, Stefan; Karlstad University, }\end{array}$ \\
\hline Keywords: & Personality, Performance, Stress, Motivation \\
\hline & \\
\hline
\end{tabular}

SCHOLARONE ${ }^{m}$

Manuscripts 
3 Profiles of perfectionism, parental climate, and burnout among competitive junior athletes

Henrik Gustafsson

Karlstad University

Andrew P. Hill

York St John University

Andreas Stenling

Umeå University

Stefan Wagnsson

Karlstad University

15 Henrik Gustafsson, Faculty of Health, Science and Technology, Karlstad University; Andrew

16 Hill, Faculty of Health and Life Sciences, York St John University; Andreas Stenling,

17 Department of Psychology, Umeå University; Stefan Wagnsson, Faculty of Health, Science

18 and Technology, Karlstad University

21 Correspondence concerning this article should be addressed to Henrik Gustafsson, Faculty of 22 Health, Science and Technology, Karlstad University, 651 88, Karlstad, Sweden. Email:

23 henrik.gustafsson@kau.se. 
Abstract

3 Recent research suggests that groups of athletes can be identified that differ in terms of

4 perfectionism and perceptions of achievement climate. Moreover, these groups also differ in

5 terms of burnout symptoms. The purpose of the current study was to extend this research by

6 examining whether discernable groups can be identified based on scores of perfectionism and

7 perceptions of parent-initiated climate and, then, whether these groups differ in terms of

8 burnout. Two-hundred and thirty-seven Swedish junior athletes (124 male and 113 female

9 aged 16-19) from a variety of sports completed measures of athlete burnout,

10 multidimensional perfectionism, and parent-initiated motivational climate. Latent profile

11 analysis identified four groups: non-perfectionistic athletes in a task-oriented climate,

12 moderately perfectionistic athletes in a task-oriented climate, highly perfectionistic athletes in

13 a task-oriented climate, and highly perfectionistic athletes in a mixed climate. The latter two

14 groups reported higher levels of burnout in comparison to other groups. The findings suggest

15 that junior athletes high in perfectionism may be at comparatively greater risk to burnout and

16 that this may especially be the case when they perceive their parents to emphasize concerns

17 about failure and winning without trying one's best.

19 Keywords: personality, performance, stress, motivation. 
Profiles of perfectionism, parental climate, and burnout among competitive junior athletes

5 as well as being an athlete (e.g., increasing training loads and competitive pressure)

6 (Gustafsson, Kenttä, \& Hassmén, 2011). As a consequence of this stressful environment,

7 junior athletes are exposed to the risk of burnout. The most widely accepted definition of

8 athlete burnout is that it is a syndrome comprised of three symptoms; emotional and physical

9 exhaustion, a reduced sense of accomplishment, and sport devaluation (Raedeke \& Smith,

10 2001). The first symptom represents the depletion of the athlete's emotional and physical

11 resources. The second symptom describes an enduring perception that sport performances

12 and abilities are deficient. The final symptom is a loss of interest, cynical attitude, and

13 devaluation of the formerly loved sport. In combination, these symptoms undermine the

14 performance, motivation, and wellbeing of athletes (Gustafsson, Hassmén, Kenttä, \&

15 Johansson, 2008).

There are a number of models that explain the onset of burnout (see Eklund \&

17 Cresswell, 2007, for a review). Arguably, the most influential has been Smith's (1986)

18 cognitive-affective model. In this model burnout is understood as part of the stress-process

19 and, principally, the result of chronic stress. Specifically, mirroring the stress process,

20 burnout is thought to develop when demands are continuously appraised to outweigh personal

21 resources and athletes are unable to employ appropriate coping strategies. In this model

22 whether burnout develops is ultimately governed by a cognitive appraisal process whereby

23 the personal meaning given to being unable to meet demands. This model has been popular in

24 sport and has received empirical support with burnout symptoms consistently and strongly 
1 associated with stress-related factors (e.g., anxiety and coping) (see Goodger, Gorely,

2 Lavallee, \& Harwood, 2007, for a review).

3 Multidimensional perfectionism

According to Smith's (1986) model, personality factors contribute to burnout via their

5 influence on the stress-process. One of the most investigated personality factors in relation to

6 athlete burnout has been perfectionism. Broadly, perfectionism is a personality that entails a

7 combination of exceedingly high standards and a preoccupation with extreme self-critical

8 evaluation (e.g., Frost, Marten, Lahart, \& Rosenblate, 1990). Perfectionism is considered to

9 be multidimensional by most researchers. This is exemplified by the approach of Frost and

10 colleagues (1990) who measure perfectionism using a combination of intrapersonal and

11 interpersonal dimensions. The two core dimensions of this model, however, are personal

12 standards (reflecting high personal standards of performance) and the tendency to evaluate

13 eneself based on performance) and concern over mistakes (a preoccupation with minor errors

14 and equating them with failure). Along with other similar dimensions, these two features

15 predict a wide array of outcomes among athletes including burnout (see Gotwals, Stoeber,

16 Dunn, \& Stoll, 2012, for review).

17 Consistent with Smith's (1986) model, one of the reasons why dimensions of

18 perfectionism are thought to be important when considering the likelihood of athlete burnout

19 is due to their influence on stress-related processes (e.g., Hill et al., 2010). Specifically,

20 concern over mistakes and similar dimensions are thought to predispose individuals to more

21 pronounced and prolonged periods of stress (Hewitt \& Flett, 2002). This is because they

22 encompass a self-evaluative process whereby continual achievement is necessary in order to

23 maintain a sense of self-worth (Greenspon, 2000). Athletic achievement therefore carries an

24 irrational sense of importance that evokes higher levels of threat and anxiety via the cognitive

25 appraisal process. As described by Lemyre, Hall, and Roberts (2008), when athletes give 
1 meaning to achievement in this manner, it is simply a matter of time before chronic and

2 overwhelming levels of anxiety develop, rendering athletes disaffected and burned out. In

3 accord with this perspective, research has found that it is not the presence of high personal

4 standards, per se, that contributes to higher burnout but the presence of high concern over

5 mistakes (for a recent meta-analysis of the perfectionism-burnout relationship, see Hill \&

6 Curran, in press).

7 While research has helped establish the perfectionism-burnout relationship, to date

8 research has largely focused on the influence of perfectionism on burnout separate from the

9 social environment in which perfectionism is exhibited. This reflects a wider absence in this

10 area which has prompted a number of researchers to note that the influence of the social

11 environment on the development of burnout has been neglected (e.g., Goodger et al., 2007).

12 Here we focus on the notion that perfectionistic junior athletes will find themselves in

13 different social environments initiated by parents and this will contribute to vulnerability to

14 burnout. We center on parents for a number of reasons. Firstly, they are known to play an

15 influential role in shaping the experience of junior athletes (Keegan, Spray, Harwood, \&

16 Lavallee, 2010). Secondly, they have also been identified as both a source of pressure or

17 potential support that may foster or waylay athlete burnout (e.g., Gould, et al., 1996; Raedeke

18 et al., 2002). Thirdly, perfectionism is thought to be acquired in part in response to parental

19 behavior with perceptions of parents' expectations and criticism so may be especially

20 relevant for adolescents (Flett, Hewitt, Oliver, \& Macdonald, 2002).

21 Achievement goal theory and parent-initiated motivational climate

Achievement goal theory (Nicholls, 1984) offers a means of understanding the

23 influence of parents on burnout. According to this theory, achievement contexts are

24 conceptualized through the goal structures and expectations that shape perspectives on

25 success, referred to as achievement climates. Ames (1992) identified two motivational 
1 climates, a task-involving climate and ego-involving climate. A task-involving climate entails

2 emphasizing and rewarding effort and cooperation, focusing on learning, and self-referenced

3 criteria for success. In contrast, an ego-involving climate entails reinforcement of social

4 comparison and evaluation, within-group competition, and punishment of mistakes. In

5 combination with dispositional tendencies to be task-involved and ego-involved (goal-

6 orientations), the motivational climate determines goal involvement and motivational

7 outcomes. In general, a task-involving climate is associated with adaptive motivation-related

8 responses and an ego-involving climate with maladaptive motivation-related responses. This

9 is evident in sport where the comparative benefits of a task-involving climate have received

10 extensive support (e.g., Harwood, Keegan, Smith, Raine, 2015; Braithwaite, Spray,

11 Warburten, 2011).

12 Along with coaches and peers, parents are an important source of motivational

13 climate (White, 1996; White, Duda, \& Hart, 1992). Parent-initiated motivational climate

14 includes three main elements: (a) learning/enjoyment, that is the extent to which parents

15 emphasize enjoyment, effort, and learning new skills; (b) worry-conducive, which is the

16 extent to which parents emphasize concerns about failure and mistakes; and (c) success-

17 without-effort, which is to what extent parents emphasize performing without trying one's

18 best. The first element reflects a task-involving climate, whereas the other two reflect an ego-

19 involving climate (White et al, 1992). Although few studies have examined parent-initiated

20 climate in sport, findings so far are similar to wider research with elements of a task-

21 involving parent-initiated climate predicting more adaptive patterns of achievement goals

22 (e.g., Morris \& Kavussanu, 2008), sportsmanship (e.g., LaVoi \& Babkes Stellino, 2008), and

23 anxiety (e.g., O’Rourke, Smith, Small, \& Cumming, 2011), in comparison to elements of an

24 ego-involving parent-initiated climate. 
1 The divergence between the two motivational climates extends to athlete burnout. In

2 describing the relationship between motivational climates and burnout, Lemyre et al. (2008)

3 argued that a task-involving climate provides situational cues that promote a desire for

4 challenge, intrinsic interest, and motivationally enhancing attributions for achievement

5 outcomes, protecting athletes from burnout. In contrast, an ego-involving climate provides

6 situational cues that promote an intense focus on validating self-worth, fosters perceptions of

7 incompetence, and heightens a sense of personal threat and anxiety, rendering athletes

8 vulnerable to burnout. Research has provided some support for these suggestions, with coach-

9 and peer-created task-involving climates typically negatively related to burnout and coach-

10 and peer-created ego-involving climates positively related to burnout (e.g., Lemyre et al.,

11 2008; Smith, Gustafsson, \& Hassmén, 2010). Surprisingly, no research to date has examined

12 the influence of parent-initiated climate on burnout; however, findings regarding motivational

13 climate more generally suggest that athletes who perceive the parent-initiated climate to be

14 more ego-involving are likely to also report higher levels of burnout.

\section{Profiles of perfectionism and motivational climate}

17 motivational climate are associated with different patterns of burnout. In this regards two

18 studies are especially relevant. Gotwals (2011) found four groups of perfectionists among

19 varsity student-athletes ('parent-oriented unhealthy perfectionists', 'doubt-oriented unhealthy

20 perfectionists', 'healthy perfectionists', and 'non-perfectionists') and that these four groups

21 exhibited differences in levels of burnout symptoms so that the healthy perfectionists group

22 was the most maladaptive. In the only study to seek to also integrate measures of the social

23 environment, Lemyre et al (2008) identified two groups among elite senior and junior athletes

24 who differed in terms of personal standards, concern over mistakes and perceptions of a

25 coach created climate, along with other motivational variables. Notably, the group who 
1 reported higher concern over mistakes and personal standards in combination with higher

2 levels of an ego-involving coach created climate and lower levels of a task-involving coach

3 created climate ('maladaptive motivation') also reported higher levels of all symptoms of

4 burnout. Consequently, research suggests that different groups of perfectionists in different

5 achievement climates can be identified and they differ in terms of athlete burnout. In seeking to identify different groups, these two studies exemplify a person-centred

7 approach. A person-oriented approach places emphasis on the individual rather than

8 variables. As such, the individual is viewed holistically and his/her interwoven characterises

9 considered simultaneously (Bergman \& Andersson, 2010). As highlighted by Gotwals

10 (2011), in context of examining perfectionism and burnout, this approach is highly

11 appropriate as it more readily treats perfectionism as a multidimensional construct and

12 identifies burnout as a phenomenon that inflicts individuals, not variables. However, Gotwals

13 (2011) and Lemyre et al (2008) also used cluster analysis. This is a useful technique when

14 seeking to identify naturally occurring groups and examine their differences but, despite its

15 strengths, it is also an exploratory technique that can provide highly unstable solutions with

16 few means of differentiating between cluster solutions objectively. For these reasons,

17 researchers have begun to utilise other techniques such as latent profile analysis. Latent

18 profile analysis offers an alternative model-based approach to identifying naturally occurring

19 groups with the notable advantages of providing probability estimates of group membership

20 and providing fit indices to differentiate between multiple possible cluster solutions (Marsh,

21 Lüdtke, Trautwein, \& Morin, 2009). In light of these advantages, we adopt this approach here

22 for the first time among research examining the relationship between perfectionism and

23 burnout.

24 In summary, the purpose of the current study was to build upon research in this area

25 that has examined perfectionism, achievement climates, and burnout, as well as research 
1 using person-oriented approaches, by (i) examining whether discernable groups can be

2 identified among junior athletes based on levels of perfectionism and perceptions of parent-

3 initiated climate in sport, and (ii) whether these groups differ in terms of athlete burnout

4 symptoms. Based on the findings of others in this area, it was expected that groups would

5 emerge that varied in both perfectionism and perceptions of parent climate and that higher

6 levels of burnout would be evident among groups that reported higher concerns over mistakes

7 and an ego-involving climate.

\section{Method}

\section{Participants and procedure}

10 Participants were 237 Swedish junior athletes (124 males, 113 females, $M$ age $=16.99$

11 years, $S D=0.80$ years, range $=16$ to 19 years $)$ recruited from a range of team $(n=178$; e.g.,

12 football, hockey, and rugby) and individual sports ( $n=59$, athletics, tennis, and swimming).

13 The athletes were recruited from a designated sport high school under the surveillance of the

14 Swedish national sport federation. The junior athletes reported that they spent $8.71(S D=$

15 5.44) hours per week training and competing and had participated in their sport for 9.08 years

$16(S D=2.71)$. Ethical approval was gained from the research ethics committee of the first

17 author's university prior to conducting the study.

\section{Instruments}

Burnout. The Athlete Burnout Questionnaire (ABQ; Raedeke \& Smith. 2001) was

20 used to measure burnout. This includes three 5-item subscales that assess three symptoms:

21 reduced sense of athletic accomplishment (RA; e.g., 'I am not performing up to my ability in

22 my sport'), emotional and physical exhaustion (EE; e.g., 'I feel overly tired from my sport

23 participation'), and sport devaluation (D; e.g., 'The effort I spend participating in my sport

24 would be better spent doing other things'). Items are measured on a 5-point Likert scale $(1=$

25 almost never to 5 = almost always). Evidence for the validity and reliability of this instrument 
1 has been provided by Raedeke and Smith (2001) via assessment of factorial structure

2 (confirmatory factor analysis) and internal consistency (all $\alpha \mathrm{s} \geq .84$ ). The scale has been used

3 in a range of sports (e.g., swimmers and soccer) and has been used with junior athletes (e.g.,

4 Hill, 2013). The Swedish version of the ABQ has shown to have acceptable factor structure

5 and internal reliability (e.g., Smith et al., 2010).

Multidimensional Perfectionism. Personal standards and concern over mistakes

7 were measured using subscales from the short-version of Frost et al.'s (1990)

8 Multidimensional Perfectionism Scale (Cox, Enns, \& Clara, 2002). Specifically, personal

9 standards (5-items, e.g., 'I set higher goals than most people.') and concern over mistakes (5-

10 items, e.g., 'If I fail partly, it is as bad as being a complete failure.') were used. Responses are

11 measured on a 5-point Likert scale $(1=$ strongly disagree to $5=$ strongly agree $)$. Evidence to

12 support the validity and reliability of the instrument has been provided by Cox et al. (2002) in

13 the form of assessing factor structure (confirmatory factor analysis) and internal consistency

$14(\alpha=.63$ to .90$)$. The subscales of the shortened version are highly correlated with the

15 originals ( $r=.87$ to .98$)$ and has the advantage of better factor structure (see Cox et al.,

16 2002). The Swedish version of MPS has been translated and successfully used with athletes

17 (e.g., Koivula, Hassmén, \& Fallby, 2002).

18 Perceived Motivational Climate. White and colleagues' (White et al., 1992; White,

19 1996, 1998) Parent-Initiated Motivational Climate Questionnaire (PIMCQ-2) was used to

20 assess perceptions of the parent-climate. This includes perceptions that the junior athletes'

21 mother or father promotes learning and enjoyment climate (LE; 9-items, e.g., 'Believes

22 enjoyment is very important in developing new skills'), a worry-conducive climate (WC; 5-

23 items, e.g., 'Makes me worried about failing.'), and a success-without-effort climate (SWE;

24 4-items, e.g., 'Says it is important for me to win without trying hard'). This scale includes 36-

25 items (18-items repeated twice and focused on either mother or father) measured on 5-point 
1 Likert scale $(1=$ strongly disagree to $5=$ strongly agree $)$. Evidence to support the reliability

2 and validity of the scale has been provided by White and colleagues (e.g., White et al., 1992;

3 White, 1996, 1998). This includes explorative factor analysis with support for the three

4 dimensional structure and internal consistency $(\alpha=.72$ to .90$)$. In the current study a Swedish

5 version was created using a 'translation-back-translation' procedure (Geisinger, 2003). The

6 original scale was translated into Swedish by a Swedish native speaker and then translated

7 back to English by a bilingual translator. Minor adjustments were made to the items

8 following this procedure. ${ }^{1}$ The two parent-climates were standardised and added together to

9 create a measure of parent climate (rather than mother of father climates). This strategy has

10 been used by others (e.g., Morris \& Kavussanu, 2008) and was adopted here because we were

11 interested in overall perceptions of parents and perceptions of the climate initiated by mothers

12 and fathers were highly correlated (LE $r=.67$, WC $r=.67$, and SWE $r=.68$ ).

\section{Statistical Analysis}

14 Initial data screening, descriptive statistics and bivariate correlations were calculated

15 with the IBM SPSS Statistics version 22. The latent profile analysis (LPA) was conducted

16 with Mplus version 7.3 (Muthén \& Muthén, 1998-2012). The LPA was conducted to uncover

17 homogenous subgroups within the sample based on their scores on the perfectionism and

18 parental climate variables (Marsh et al., 2009; Pastor, Barron, Miller, \& Davis, 2007). These

19 subgroups are considered latent because the participants' class membership is not directly

20 observed but instead inferred from the relationship between the measured variables.

21 Following Marsh et al. (2009) recommendations, we estimated solutions with varying

22 numbers of classes and selected the solution that made most sense in relation to theory,

23 previous research, interpretability of the classes, and also statistical criteria. We used nested

24 model comparisons and tested whether more complex models (i.e., more classes) had a better

25 fit to the data than more parsimonious models (i.e., fewer classes). In this study we estimated 
$1 \quad 1-6$ classes to identify the appropriate number of classes. A number of statistical criteria were

2 used to asses model fit. The Bootstrap Likelihood Ratio Test (BLRT) was used to compare a

$3 k$-class model with a $k-1$ class model. A significant BLRT $p$ value indicates a better model fit

4 for $k$-class model compared to the $k$-1 class model (Nylund, Muthén, \& Asparouhov, 2007).

5 The Bayesian Information Criterion (BIC) and sample-size adjusted BIC (SSA-BIC) were

6 also used and are relative measures of how well a model fit the data with lower values

7 indicating a better model fit (Raftery, 1995). To examine the precision of the classification of

8 the participants into classes, entropy values were used (Ramaswamy, DeSarbo, Reibstein, \&

9 Robinson, 1993). Entropy values range from 0 to 1 where a higher value indicates better

10 precision (Berlin, Williams, \& Parra, 2013). To further examine the precision of the latent

11 class categorization, the average latent class probabilities were also inspected. Although no

12 clear cut-offs have been proposed, Berlin et al. (2013) suggested that probabilities of .85 and

13 higher indicate some degree of adequacy. In determining the appropriate number of classes,

14 we considered the numbers of cases within each class as small numbers are considered less

15 feasible (Berlin et al., 2013; Marsh et al. 2009). We used 500 random start values for each

16 model, with the 50 best retained for the final solution. To avoid local maxima the final

17 solution was replicated with 1500 random start values (Geiser, 2013).

18 A multivariate analysis of variance (MANOVA) was used to examine differences

19 between the classes in terms of perfectionism and climate variables. This was followed by

20 univariate analyses and pairwise Bonferroni corrected comparisons with $95 \%$ bias corrected

21 bootstrap estimates of differences between classes. These were necessary so as to compensate

22 for lack of homogeneity of covariance between groups and associated increased risk of type 1

23 error (Finch, 2005). An overall test and pairwise class comparisons between the latent class

24 categorization and the three burnout symptoms were conducted using a Wald chi-square test

25 (DU3STEP in Mplus). This procedure is referred to as the three-step method and uses 
1 auxiliary variables (i.e., the three burnout symptoms) as distal outcomes that are compared

2 between the classes (Asparouhov \& Muthén, 2014). Bonferroni correction of the significance

3 level $(.05 / 6=.008)$ was applied within each of the burnout symptoms to reduce the risk of

4 type 1 errors due to multiple tests.

5

\section{Preliminary Analysis}

\section{Descriptive statistics}

\section{Results}

Prior to the main analyses, a missing value analysis was conducted on the data. Due to large amounts of missing data (> 5\%), 20 participants were removed from the sample. Subsequently, there were then 209 complete cases and 8 cases with incomplete data. For those with incomplete data, the average number of missing values was the equivalent of less than 2 items $(M=1.13, S D=0.35$, range 1 to 2$)$. An inspection of the pattern of missing data suggested a non-systematic mechanism for the missing data. Specifically, only two common missing data patterns were evident (i.e., the same two items missing) with all other individuals displaying a unique pattern (i.e., missing different items). Consequently, the missing data was considered as missing at random and estimated using the full information maximum likelihood (FIML) function (Enders, 2010). Following this procedure, the data was then screened for univariate outliers (standardised $z$-scores larger than $3.29, p<.001$, twotailed) using the protocol described by Tabachnick and Fidell (2007). This led to the removal of 1 of the participants. In the absence of outliers, the data was considered sufficiently univariate normal. Finally, internal reliability analysis (Cronbach's alpha) indicated that all instruments demonstrated adequate internal consistency $(\alpha=.69$ to .94 , see Table 1$)$.

Descriptive statistics are reported in Table 1. Overall, the junior athletes reported moderate-to-high perceptions of a parent-initiated climate that was task-oriented, low levels of a parent-initiated climate that was worry conducive, and moderate-to-low levels of a 
1 parent-initiated climate that emphasised success-without-effort. The athletes reported low

2 levels of concern over mistakes and moderate levels of personal standards. They also reported

3 low-to-moderate levels of symptoms of burnout. A parent-initiated task-oriented climate was

4 negatively related to concern over mistakes. A parent-initiated climate that was worry

5 conducive was positively associated with concern over mistakes, personal standards, and all

6 three burnout symptoms, whereas a climate that emphasised success-without-effort was

7 positively related to concern over mistakes and two of the burnout symptoms (EXH and

8 DEV). Personal standards and concern over mistakes were positively related to all burnout

9 symptoms.

10 Latent Profile Analysis

11 The model fit of the six estimated latent profile solutions are displayed in Table 2.

12 According to the statistical criteria, the model fit improved for each successive class that was

13 added. Although the five-class solution, and to some extant the six-class solution, indicated a

14 slight improvement in model fit, they contained very small classes $(n \approx 11)$. Therefore, in

15 order to avoid the possibility of low power and precision, we choose to retain a more

16 parsimonious solution (Berlin et al., 2013). Hence, based on the combination of statistical

17 criteria and interpretability, we retained the four-class solution as our final model.

18 Using the four-class solution, distinct profiles based on the athletes' perfectionism and

19 climate scores were generated (Table 3). Athletes in class 1 reported high levels of task-

20 oriented climate and moderate levels of worry-conducive climate, success-without-effort

21 climate, concern over mistakes, and personal standards. Class 1 is labeled as "moderately

22 perfectionistic athletes in a task-oriented climate". Athletes in class 2 reported relatively high

23 levels on task-oriented climate and relatively low levels on worry-conducive climate,

24 success-without-effort climate, concern over mistakes, and personal standards. Class 2 is

25 labeled as "non-perfectionistic athletes in a task-oriented climate". Athletes in class 3 
1 reported relatively high levels on task-oriented climate, low levels on worry-conducive

2 climate and success-without-effort climate, and relatively high levels on concern over

3 mistakes and personal standards. Class 3 is labeled as "highly perfectionistic athletes in a

4 task-oriented climate". Finally, athletes in class 4 reported relatively high levels on the

5 perceived parental climate and the perfectionism variables. Class 4 is labeled as "highly

6 perfectionistic athletes in a mixed climate".

The MANOVA showed that there were significant differences between the classes in

8 terms of the combination of variables: Pillai's Trace $(15,630)=0.99, p<.001)$. Follow-up

9 univariate tests confirmed differences between classes for all variables: concern over

10 mistakes, $F(3,212)=195.25$, personal standards, $F(3,212)=36.37$, $\operatorname{LOC} F(3,212)=$

11 13.51, WCC, $F(3,212)=496.85$, and SWE, $F(3,212)=18.11, p s<.001$. Bonferroni

12 pairwise comparisons are displayed in Table 3. Class 1 reported lower levels of task-oriented

13 climate and higher levels of worry-conducive climate and success-without effort climate

14 compared to class 2 and class 3. Class 1 also reported lower levels of worry-conducive

15 climate compared to class 4 , higher levels of concerns over mistakes and personal standards

16 compared to class 2, and reported lower levels of concern over mistakes and personal

17 standards compared to class 3 and 4. Class 2 reported higher levels of task-oriented climate

18 and lower levels of worry-conducive climate and success-without effort climate compared to

19 class 4. Class 2 also reported lower levels of success-without effort climate compared to class

204 and reported lower levels of concerns over mistakes and personal standards compared to

21 class 3 and class 4 . Class 3 reported higher levels of task-oriented climate and lower levels of

22 worry-conducive climate and success-without effort climate compared to class 4 . Class 3 also

23 reported higher levels of personal standards compared to class 4.

As seen in Table 4, the Wald chi-square tests showed that there were statistically

25 significant overall differences between the four classes in all self-reported burnout symptoms. 
1 Specific pairwise comparisons showed that the moderately perfectionistic athletes in a task-

2 oriented climate $(\mathrm{C} 1)$ reported lower levels of reduced sense of accomplishment and

3 exhaustion compared to the highly perfectionistic athletes in a mixed climate (C4). The non-

4 perfectionistic athletes in a task-oriented climate $(\mathrm{C} 2)$ reported lower levels on reduced sense

5 of accomplishment and devaluation compared to the highly perfectionistic athletes in a task-

6 oriented climate (C3) and lower levels on all three burnout symptoms compared to the highly

7 perfectionistic athletes in a mixed climate $(\mathrm{C} 4)$.

\section{Discussion}

9 The purpose of the current study was to (i) examine whether discernable groups could

10 be identified among junior athletes based on levels of perfectionism and perceptions of

11 parent-initiated climate in sport, and (ii) whether these groups differed in terms of athlete

12 burnout symptoms. It was hypothesized that groups would emerge that varied in both

13 perfectionism and perceptions of parent climate and that higher levels of burnout would be

14 evident among groups that reported higher concerns over mistakes and perceptions of an ego-

15 involving climate. In partial support of these hypotheses, four groups emerged that varied in

16 level of perfectionism and, to a lesser degree, perceptions of the achievement climate and

17 groups that were characterized by higher perfectionism and comparable levels of an ego-

18 involving climate to a task-involving climate reported higher levels of burnout

19 In line with the first hypothesis, the four groups that emerged varied in terms of level

20 of perfectionism they reported and in perceptions of the parent-initiated motivational climate.

21 This included non-perfectionistic, moderately perfectionistic, and highly perfectionistic junior

22 athletes who perceived largely task-involving climates or a mixed climate. The groups cannot

23 be directly compared to groups from other research as the measures used to classify

24 participants are different. However, the findings are consistent with other studies such as

25 Gotwals (2011) and Lemyre et al (2008) in that, when using a person-oriented approach, 
1 groups can be identified that differ in terms of perfectionism and measures of the social

2 environment. Notably, for the first time we illustrate that this includes perceptions of the 3 parent initiated climate.

4 Based on differences between the groups in terms of perfectionism and perceptions of

5 the parent-initiated climate, differences emerged in terms of burnout symptoms. This was

6 evident in two ways. Firstly, the presence of higher levels of perfectionism corresponded with

7 the presence of comparatively higher levels of burnout regardless of the level of task-

8 involving climate. Secondly, the only group to report similar levels of an ego-involving

9 climate to a task-involving climate alongside high perfectionism reported higher burnout than

10 two of the other groups. These findings suggest that higher perfectionism among junior

11 athletes might be a risk factor for higher burnout and this may especially be the case when

12 perceptions of an ego-involving climate are comparable to perceptions of a task-involving

13 climate initiated by parents.

14 The findings were limited to groups of perfectionistic junior athletes who perceived

15 largely task-involving climates. The tendency of junior athletes to report relatively higher

16 task-involving climates is a common finding in research and has also been found in terms of

17 parent initiated climate (e.g., Kavussanu, White, Jowett, \& England, 2011). Therefore, in this

18 regard, this particular finding is unsurprising. However, as a result we cannot comment on the

19 influence of an increasingly ego-involving climate (unaccompanied by a task-involving

20 climate) on burnout symptoms. Lemyre et al (2008) identified a group of athletes who

21 reported higher perfectionism and higher perceptions of an ego-involving climate. Why such

22 a group did not emerge here might reflect a number of differences between the two studies.

23 For example, Lemyre et al included elite senior athletes and focused on coach created

24 climates. It may be that in elite senior contexts and when coaches are assessed, perceptions of 25 more ego-involving climates are more likely or varied. Equally, our more robust model-based 
approach to identifying groups (i.e., latent class analysis) may explain the difference in

2 findings. Future studies are required to examine these possibilities.

\section{Applied implications}

4 Our findings point to the importance of intervention aimed at altering the behaviors of

5 parents of junior athletes. There are only a very small number of intervention studies in sport

6 that have included parents (e.g., Harwood \& Swain, 2002; Smoll, Smith, \& Cumming, 2007).

7 However, these have provided support for the notion that educational programmes can be

8 used to change parental behavior and that the effects can be seen in junior athletes. In terms

9 of the focus of any intervention, as perfectionism may prove more difficult to change,

10 promoting a more optimal motivational atmosphere by discouraging an ego-involving climate

11 and encouraging a task-involving climate may be more fruitful in terms of reducing burnout.

12 This includes, for example, setting goals that emphasize task mastery and effort and

13 deemphasize interpersonal competition and comparative ability. For the practicalities of

14 doing so, readers are deferred to the studies cited above as they adopted interventions based

15 on achievement goal theory in parents and to other studies that have done so with coaches

16 (e.g., Smith, Cumming, \& Smoll, 2007). These studies offer both empirical support and some

17 practical guidance for implementing interventions based on this theory.

\section{$18 \quad$ Limitations and other future studies}

19 The study is cross-sectional and therefore causality cannot be inferred from the

20 relationships between the variables. Longitudinal research can help address this issue.

21 Perfectionism was also measured at a general level, rather than domain-specific level. This

22 was primarily because we used the only measure of perfectionism that has been translated

23 into Swedish and used in research in this area. Although perfectionistic tendencies of athletes

24 can be measured at a global level (e.g., Gaudreau \& Antl, 2008), research suggests that

25 domain-specific measurement may be best as individuals tend to express perfectionism in 
1 specific areas of their lives (e.g., Dunn, Causgrove Dunn, \& McDonald, 2012). Therefore,

2 once translated, researchers may wish to use domain-specific instruments to replicate the

3 current study. Another noteworthy issue in this regard is that we used two specific

4 dimensions of perfectionism from an array available. Other instruments and dimensions may

5 result in the identification of different groups (e.g., doubt-oriented perfectionists; Gotwals,

6 2011). Therefore, our findings are likely to capture only a few of the multiple groups of

7 perfectionists that may exist. Finally, as in most other research in this area, the levels of

8 burnout observed was not high, even in the high perfectionism groups. As such, our findings

9 speak to comparative risk or vulnerability to burnout, rather than burnout per se.

10 Perspectives

11 The findings build upon research that has used person-oriented approaches to identify

12 groups of junior athletes who differ in terms of perfectionism and perceptions of the social

13 environment and illustrated that these groups differ in terms of burnout. Consistent with this

14 research, in the current study junior athletes with varying degrees of perfectionism and

15 perceptions of a parent-initiated climate also reported different levels of burnout. Higher

16 levels of perfectionism regardless of the parent-initiated climate corresponded with higher

17 levels of burnout. In addition, junior athletes with higher perfectionism and comparable levels

18 of an ego-involving climate to task-involving climate reported the highest levels of burnout.

19 The findings suggest that junior athletes high in perfectionism may be at comparatively

20 greater risk to burnout and that this may especially be the case when they perceive their

21 parents to emphasize concerns about failure and winning without trying one's best.

\section{Footnotes}

$23{ }^{1}$ Confirmatory factor analysis indicated that the initial model provided unacceptable fit: $\chi^{2}$ $24{ }_{(132)}=467.98, p<.001, \mathrm{CFI}=.85, \mathrm{NNFI}=.83, \mathrm{RMSEA}=.11,90 \% \mathrm{CI} .10$ to $.12, \mathrm{SRMR}=$ 25 .14. Subsequently, 3 items from the learning and enjoyment climate subscale were removed 
1 due to low factor loadings (<.30): Item 1 ("Is most satisfied when I learn something new"),

2 item 5 ("Pays special attention to whether I'm improving my skills"), and item 7, ("makes

3 sure that I learn one thing before teaching me another"). The resulting model provided

4 acceptable fit: $\chi_{(87)}^{2}=252.84, p<.001, \mathrm{CFI}=.92, \mathrm{NNFI}=.90, \mathrm{RMSEA}=.09,90 \% \mathrm{CI} .08$ to

$5.11, \mathrm{SRMR}=.09$.

6

\section{References}

Ames C. Motivational climate and achievement-related patterns. In Roberts GC, ed. Motivation in Sport and Exercise. Champaign, IL: Human Kinetics, 1992: 161-176.

Asparouhov T, Muthén B. Auxiliary variables in mixture modeling: Three-step approaches using Mplus. Structural Equation Modeling: A Multidisciplinary Journal 2014, 21, 329-341.

Bergman LR, Andersson H. The person and the variable in developmental psychology. J Psychol 2010: 218: 155-165.

Berlin KS, Williams NA, Parra GR. An introduction to latent variable mixture modeling (part 1): Overview and cross-sectional latent class and latent profile analyses. J Pediatr Psychol 2014: 39, 174-187.

Braithwaite R, Spray CM, Warburton VE. Motivational climate interventions in physical education: A meta-analysis. Psychol Sport Exerc 2011: 12: 628-638.

Cox BJ, Enns MW, Clara IP. The multidimensional structure of perfectionism in clinically distressed and college student samples. Psychological Assessment 2002: 14: 365-373.

Dunn JGH, Dunn JC, McDonald K. Domain-specific perfectionism in intercollegiate athletes: Relationships with perceived competence and perceived importance in sport and school. Psychol Sport Exerc 2012: 13: 747-755.

Eklund RC, Cresswell SL. Athlete burnout. In Tenenbaum G, Eklund RC, eds. Handbook of Sport Psychology. New York: Wiley \& Sons, 2007: 621-641. 
1 Enders CK. Applied missing data analysis. New York: Guilford Press, 2010.

2 Flett GL, Hewitt PL, Oliver JM, Macdonald S. Perfectionism in children and their parents:

3

A developmental analysis. In Flett GL, Hewitt PL, eds. Perfectionism: Theory, Research and Treatment. Washington, DC: American Psychological Association, 2002: 89-132.

Finch H. Comparison of the performance of nonparametric and parametric MANOVA test statistics when assumptions are violated. Methodology: European Journal of Research Methods for the Behavioral and Social Sciences 2005: 1: 27-38.

Frost RO, Marten PA, Lahart C, Rosenblate R. The dimensions of perfectionism. Cog Therapy Res 1990:14: 449-468

Gaudreau P, Antl S. Athletes' broad dimensions of dispositional perfectionism: Examining changes in life satisfaction and the mediating role of sport-related motivation and coping. J Sport Exerc Psychol 2008: 30: 356-382.

Geiser, C. (2013). Data analysis with Mplus. New York, NY: Guilford Press.

Geisinger KF. Testing and assessment in cross-cultural psychology. In Graham, JR, Naglieri JA, eds. Handbook of psychology. Hoboken, NJ: Wiley, 2003: 10: 95-118.

Goodger K, Gorely T, Lavallee D, Harwood C. Burnout in Sport: A systematic review. Sport Psychol 2007: 21: 127-151.

Gotwals JK. Perfectionism and burnout within intercollegiate sport: A person-oriented approach. Sport Psychol 2011: 25: 489-510.

Gotwals JK, Stoeber J, Dunn JGH, Stoll O. Are perfectionistic strivings in sport adaptive? A systematic review of confirmatory, contradictory, and mixed evidence. Canadian Psychology 2012: 53: 263-279.

Gould D, Udry E, Tuffey S, Loehr J. Burnout in competitive junior tennis players: I. A quantitative psychological assessment. Sport Psychol 1996:10: 322-340. 
1 Greenspon TS. "healthy perfectionism" is an oxymoron! Reflections on the psychology of perfectionism and the sociology of science. The Journal of Secondary Gifted Education 2000: 11: 197-208.

Gustafsson H, Hassmén P, Kenttä G, Johansson M. A qualitative analysis of burnout in elite Swedish athletes. Psychol Sport Exerc 2008: 9: 800-816.

Gustafsson H, Kenttä G, Hassmén P. Athlete burnout: An integrated model and future research directions. International Review of Sport and Exercise Psychology 2011: 4: 3-24.

Harwood C, Swain A. The development and activation of achievement goals within tennis: a player, parent and coach intervention. Sport Psychol 2002: 16: 111-137.

Hewitt PL, Flett GL. Perfectionism and stress processes in psychopathology. In Flett, GL, Hewitt PL, eds. Perfectionism: Theory, Research and Treatment. Washington, DC: American Psychological Association, 2002: 255-284.

Hill AP. Perfectionism and burnout in junior soccer players: A test of the 2 x 2 model of dispositional perfectionism. J Sport Exerc Psychol 2013: 35: 18-29.

Hill AP. Curran T. Multidimensional Perfectionism and Burnout: A Meta-Analysis. Pers Soc Psychol Rev in press: doi:10.1177/1088868315596286

Hill AP, Hall HK, Appleton PR. Perfectionism and athlete burnout in junior elite athletes: The mediating role of coping tendencies. Anxiety Stress \& Coping 2010: 23: 415-430.

Kavussanu M, White SA, Jowett S, England S. Elite and non-elite male footballers differ in goal orientation and perceptions of parental climate. International Journal of Sport and Exercise Psychology 2011: 9: 284-290.

Keegan R, Spray C, Harwood C, Lavallee D. The motivational atmosphere in youth sport: Coach, parent, and peer influences on motivation in specializing sport participants. J Appl Sport Psychol 2010: 22: 87-105. 
1 Koivula N, Hassmén P, Fallby J. Self-esteem and perfectionism in elite athletes: Effects on competitive anxiety and self-confidence. Personality and Individual Differences 2002: 32: $865-875$.

LaVoi NM, Babkes Stellino M. The influence of perceived parent created sport climate on competitive youth male hockey players' good and poor sport behaviors. Journal of Psychology: Interdisciplinary \& Applied 2008: 142: 471-495.

Lemyre, P-N., Hall, H. K., \& Roberts, G. C. (2008). A social cognitive approach to burnout

Morris RL, Kavussanu M. Antecedents of approach-avoidance goals in sport. J Sports Sci Journal 2009:16:191-225.

Marsh HW, Lüdtke O, Trautwein U, Morin AJ. Classical latent profile analysis of academic self-concept dimensions: Synergy of person-and variable-centered approaches to theoretical models of self-concept. Structural Equation Modeling: A Multidisciplinary 2008: 26: 465-476.

Muthén LK, Muthén BO. Mplus user's guide (7th ed.). Los Angeles, CA: Muthen \& Muthen. 1998-2012.

Nicholls JG. Achievement motivation: Conceptions of ability, subjective experience, task choice, and performance. Psychol Rev 1984: 91: 328-346.

Nylund KL, Asparouhov T, Muthén BO. Deciding on the number of classes in latent class analysis and growth mixture modeling: A Monte Carlo simulation study. Structural Equation Modeling: A Multidisciplinary Journal 2007: 14: 535-569.

O’Rourke DJ, Smith RE, Smoll FL, Cumming SP. Trait anxiety in young athletes as a function of parental pressure and motivational climate: Is parental pressure always harmful? J Appl Sport Psychol 2011: 23: 398-412. 
1 Pastor DA, Barron KE, Miller BJ, Davis SL. A latent profile analysis of college students' achievement goal orientation. Contemporary Educational Psychology 2007: 32: 8-47.

Raedeke TD, Smith AL. Development and preliminary validation of an athlete burnout measure. J Sport Exerc Psychol 2001: 23: 281-306.

Raftery A. Bayesian model selection in social research. Sociological Methodology 1995: 25: 111-163.

Smith RE. Toward a cognitive-affective model of athletic burnout. J Sport Psychol 1986: 8: 36-50.

Smith AL, Gustafsson H, Hassmén P. Peer motivational climate and burnout perceptions of adolescent athletes, Psychol Sport Exerc 2010: 11: 453-460.

\section{Smith RE, Smoll FL, Cumming, SP. Effects of a motivational climate intervention for} coaches on young athletes' sport performance anxiety. J Sport Exerc Psychol 2007: 29: $39-59$.

Smoll FL, Smith, RE, Cumming SP. Effects of coach and parent training on performance anxiety in young athletes: A systemic approach. Journal of Youth Development, 2007: 2, 0701FA002.

Tabachnick BG, Fidell LS. Using multivariate statistics (5th ed.). Boston, MA: Allyn and Bacon. 2007

White SA, Duda JL, Hart S. An exploratory examination of the parent-initiated motivational climate questionnaire. Percept Mot Skills 1992: 75: 875-88.

White SA. Goal orientation and perceptions of the motivational climate initiated by parents. 
Table 1

Descriptives, Coefficient Alphas, and Bivariate Correlations of the Study Variables $(N=216)$

\begin{tabular}{lccccccccc}
\hline & $M(S D)$ & $\alpha$ & 1 & 2 & 3 & 4 & 5 & 6 & 7 \\
\hline 1. LE & $3.98(0.71)$ & .88 & & & & & & & \\
2. WCC & $1.77(0.86)$ & .94 & $-.32 * * *$ & & & & & & \\
3. SWE & $2.48(0.71)$ & .75 & -.10 & $.46^{* * *}$ & & & & & \\
4. COM & $2.24(0.94)$ & .85 & $-.14 *$ & $.46 * *$ & $.18 * *$ & & & & \\
5. PS & $2.77(0.90)$ & .80 & .10 & $.27 * * *$ & .12 & $.68 * * *$ & & & \\
6. RA & $2.59(0.69)$ & .69 & -.08 & $.32 * * *$ & .10 & $.48 * * *$ & $.49 * * *$ & & \\
7. EXH & $2.41(0.94)$ & .90 & -.07 & $.32 * * *$ & $.17 *$ & $.49 * * *$ & $.31 * * *$ & $.37 * * *$ & \\
8. DEV & $2.33(0.96)$ & .85 & -.11 & $.36^{* * *}$ & $.26 * * *$ & $.45 * * *$ & $.65^{* * *}$ & $.62 * * *$ & $.57 * * *$ \\
\hline
\end{tabular}

Notes. L/E = Learning/enjoyment climate, $\mathrm{WCC}=$ worry-conducive climate, $\mathrm{SWE}=$ success without effort climate, $\mathrm{COM}=$ concern over mistakes, PS $=$ personal standards, $\mathrm{RA}=$ reduced sense of accomplishment, $\mathrm{EXH}=$ exhaustion, $\mathrm{DEV}=$ devaluation . 
Table 2

Fit Indices of the Different Latent Profile Solutions $(N=216)$

\begin{tabular}{lllll}
\hline & & & \multicolumn{2}{l}{ BLRT } \\
Classes & BIC & SSA-BIC & Entropy & $p$ value \\
\hline 1 & 2674.707 & 2643.019 & NA & NA \\
2 & 2498.686 & 2447.984 & .907 & .000 \\
3 & 2473.343 & 2403.629 & .940 & .000 \\
$\mathbf{4}$ & $\mathbf{2 4 4 6 . 0 1 0}$ & $\mathbf{2 3 5 7 . 2 8 2}$ & $\mathbf{. 8 7 9}$ & $\mathbf{. 0 0 0}$ \\
5 & 2431.835 & 2324.094 & .892 & .000 \\
6 & 2439.511 & 2312.758 & .834 & .008 \\
\hline
\end{tabular}

Average Latent Class Probabilities for Most Likely Latent Class Membership

\begin{tabular}{|c|c|c|c|c|c|c|c|}
\hline Two-class model & $\approx n(\%)^{\mathrm{a}}$ & Class 1 & Class 2 & Class 3 & Class 4 & Class 5 & Class 6 \\
\hline Class 1 & $145.0(67.1)$ & .984 & .016 & & & & \\
\hline Class 2 & $71.0(32.9)$ & .047 & .953 & & & & \\
\hline \multicolumn{8}{|l|}{ Three-class model } \\
\hline Class 1 & $63.8(29.6)$ & .949 & .026 & .024 & & & \\
\hline Class 2 & $135.7(62.8)$ & .007 & .993 & .000 & & & \\
\hline Class 3 & $16.4(7.6)$ & .071 & .000 & .929 & & & \\
\hline \multicolumn{8}{|l|}{ Four-class model } \\
\hline Class 1 & $25.7(11.9)$ & .890 & .001 & .100 & .010 & & \\
\hline Class 2 & $28.6(13.2)$ & .000 & .899 & .000 & .101 & & \\
\hline Class 3 & $111.1(51.4)$ & .035 & .000 & .960 & .005 & & \\
\hline Class 4 & $50.6(23.4)$ & .008 & .049 & .023 & .920 & & \\
\hline \multicolumn{8}{|l|}{ Five-class model } \\
\hline Class 1 & $107.1(49.6)$ & .959 & .035 & .006 & .000 & .000 & \\
\hline Class 2 & $27.9(12.9)$ & .114 & .880 & .006 & .000 & .000 & \\
\hline Class 3 & $40.0(18.5)$ & .010 & .008 & .930 & .052 & .000 & \\
\hline Class 4 & $29.9(13.9)$ & .000 & .003 & .094 & .885 & .018 & \\
\hline Class 5 & $11.0(5.1)$ & .000 & .000 & .005 & .045 & .950 & \\
\hline \multicolumn{8}{|l|}{ Six-class model } \\
\hline Class 1 & $32.3(14.9)$ & .833 & .167 & .000 & .000 & .000 & .000 \\
\hline Class 2 & $80.9(37.4)$ & .085 & .868 & .038 & .008 & .000 & .000 \\
\hline Class 3 & $21.9(10.1)$ & .000 & .076 & .919 & .004 & .000 & .000 \\
\hline Class 4 & $39.5(18.3)$ & .000 & .014 & .005 & .926 & .055 & .000 \\
\hline Class 5 & $30.3(14.0)$ & .000 & .000 & .002 & .083 & .896 & .020 \\
\hline Class 6 & $11.2(5.2)$ & .000 & .000 & .000 & .005 & .037 & .958 \\
\hline
\end{tabular}


Table 3

Description (M, S.E.) of the Four Latent Classes $(N=216)$

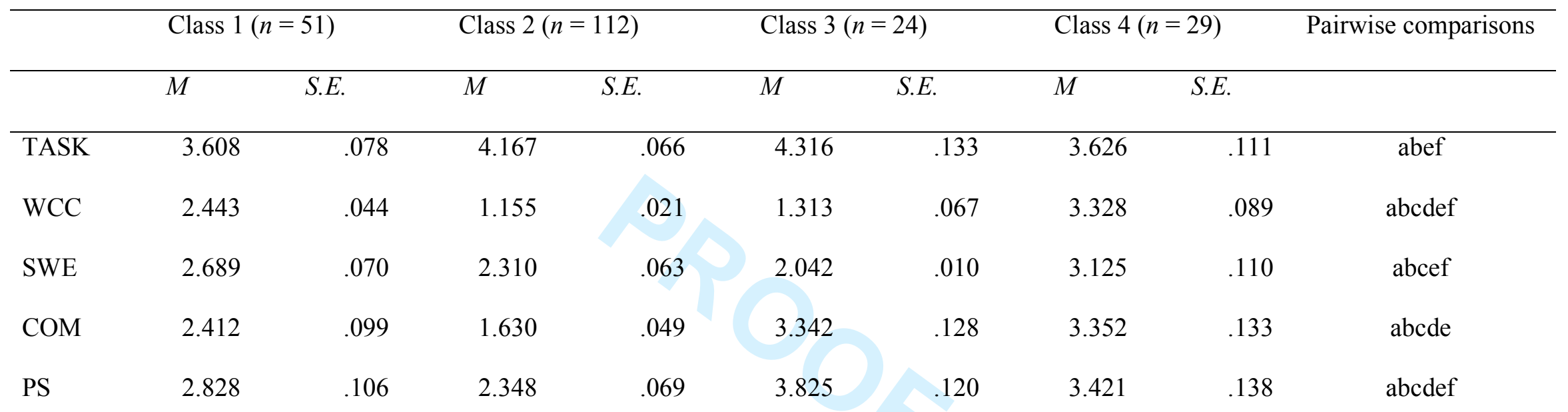

Note. $\mathrm{a}=$ class 1 differs from class $2, \mathrm{~b}=$ class 1 differs from class $3 ; \mathrm{c}=$ class 1 differs from class $4 ; \mathrm{d}=$ class 2 differs from class $3 ; \mathrm{e}=$ class 2 differs from class $4 ; \mathrm{f}=$ class 3 differs from class $4 ;$ S.E. and comparisons are based on 95\% bias-corrected bootstrapped estimates. TASK $=$ taskoriented climate, $\mathrm{WCC}=$ worry-conducive climate, $\mathrm{SWE}=$ success without effort climate, $\mathrm{COM}=$ concern over mistakes, $\mathrm{PS}=$ personal standards. 
Table 4

Description of the Four Latent Classes and $\chi^{2}$ test for Differences between the Classes in Burnout Symptoms $(N=216)$

\begin{tabular}{lcccccc}
\hline & \multicolumn{2}{c}{ RA } & \multicolumn{2}{c}{ EXH } & \multicolumn{2}{c}{ DEV } \\
& $M$ & S.E. & $M$ & S.E. & $M$ & S.E. \\
\hline Class 1 & 2.562 & .105 & 2.516 & .144 & 2.403 & .164 \\
Class 2 & 2.344 & .064 & 2.051 & .114 & 1.976 & .097 \\
Class 3 & 2.975 & .137 & 2.858 & .279 & 2.719 & .237 \\
Class 4 & 3.295 & .070 & 3.227 & .083 & 3.254 & .329 \\
\hline
\end{tabular}

\begin{tabular}{lrrrrrr} 
& \multicolumn{2}{c}{ RA } & \multicolumn{2}{c}{ EXH } & \multicolumn{2}{c}{ DEV } \\
\hline Class comparisons & \multicolumn{1}{c}{$\chi^{2}$} & $p$ value & \multicolumn{1}{c}{$\chi^{2}$} & $p$ value & \multicolumn{1}{c}{$\chi^{2}$} & $p$ value \\
\hline Overall test & 104.544 & .000 & 80.560 & .000 & 27.185 & .000 \\
1 vs. 2 & 3.094 & .079 & 6.104 & .013 & 4.854 & .028 \\
1 vs. 3 & 5.651 & .017 & 1.189 & .276 & 1.199 & .273 \\
1 vs. 4 & 32.312 & .000 & 16.703 & .000 & 3.710 & .054 \\
2 vs. 3 & 15.369 & .000 & 5.278 & .022 & 6.929 & .008 \\
2 vs. 4 & 101.669 & .000 & 69.408 & .000 & 14.025 & .000 \\
3 vs. 4 & 4.327 & .038 & 1.599 & .206 & 1.745 & .187 \\
\hline
\end{tabular}

Note. The significance level was Bonferonni corrected within each variable (.05/6) and set to .008. RA = reduced sense of accomplishment, EXH = exhaustion, $\mathrm{DEV}=$ devaluation. 